\title{
Chapter 19 \\ Quantifying the Potential of Industrial Symbiosis: The LOCIMAP Project, with Applications in the Humber Region
}

\author{
Malcolm Bailey and Andrew Gadd
}

\begin{abstract}
The Humber region, in North East England, is a major hub of industrial activity and trade. It has seen applications of industrial symbiosis for many years, initially centred on 'top-down' infrastructure projects with large capital investment but subsequently following a 'bottom-up' approach engaging industries in the area. Reductions in GHG emissions and waste generation have already been impressive. The possibilities for further savings, recognising the European Union's aspirations for deep GHG cuts and the objectives of the A.SPIRE partnership involving 114 stakeholders from the process industries in Europe, have been explored in the LOCIMAP (low-carbon industrial manufacturing parks) project, which involved partners from across Europe. Industrial symbiosis has been central in the plans for LOCIMAP from the outset. Studies conducted for LOCIMAP have revealed that more substantial savings require industrial symbiosis to be designed in, rather than developed once facilities exist. Major further savings depend on co-location of activities in eco-industrial parks to enable systematic process integration, but following this approach raises further questions, including:

- How can such systems be engineered without compromising safety?

- What are the implications for system resilience?

- How does close integration affect operations such as maintenance?

The project has shown that we have the engineering ability to achieve deep reductions in energy use and GHG emissions provided industries can be located in eco-industrial parks with interactions designed according to thermodynamic principles. Barriers to realising this concept, to achieve a new industrial revolution, include an economic and fiscal system which means that design for optimal economic performance leads to different outcomes from designing for optimal environmental performance.
\end{abstract}

Keywords Eco-industrial parks • Energy integration • Humberside • Industrial symbiosis $\bullet$ Resource innovation

M. Bailey $(\varangle) \bullet$ A. Gadd

Link2Energy Ltd, 1-3 Bigby Street, DN20 8EJ Brigg, North Lincolnshire

e-mail: malcolm@link2energy.co.uk; andrew@link2energy.co.uk

R. Clift, A. Druckman (eds.), Taking Stock of Industrial Ecology,

DOI 10.1007/978-3-319-20571-7_19 


\section{Introduction: Brief History of Industrial Symbiosis in the Humber Region}

The Humber is the largest river system in the UK and is responsible for draining $20 \%$ of the UK's land mass. It captures drainage waters as far south as Birmingham through the Trent River system and north into Yorkshire through the Ouse. The river itself is the boundary between Yorkshire and Northern Lincolnshire. It is a major navigation channel and its banks are home to significant industrial clusters. The natural geography and geology of the Humber bring significant advantages for the location of industry. The deep water channel swings first to the south bank and then to the north. The ports of Immingham, Grimsby and Hull are located at these touching points and in combination make up the largest tonnage port complex in the UK. Twenty-seven per cent of UK's refining capacity is located here; $25 \%$ of UK's rail freight originates here, much of which finds home in the steel and power industries; just north of the Humber estuary, $20 \%$ of UK's gas is landed at Easington, fed by the Langeled pipeline, the world's longest underwater pipeline, via the Sleipner gas processing platform (Fig. 19.1).

In addition to ports and logistics, the chemical industry is a highly significant cluster. With a turnover of $£ 6$ billion, it provides employment for 10,000 people within 120 companies that include global brands such as BP and Croda Chemicals. The food sector, based historically on the fishing industry, has been dominant in the

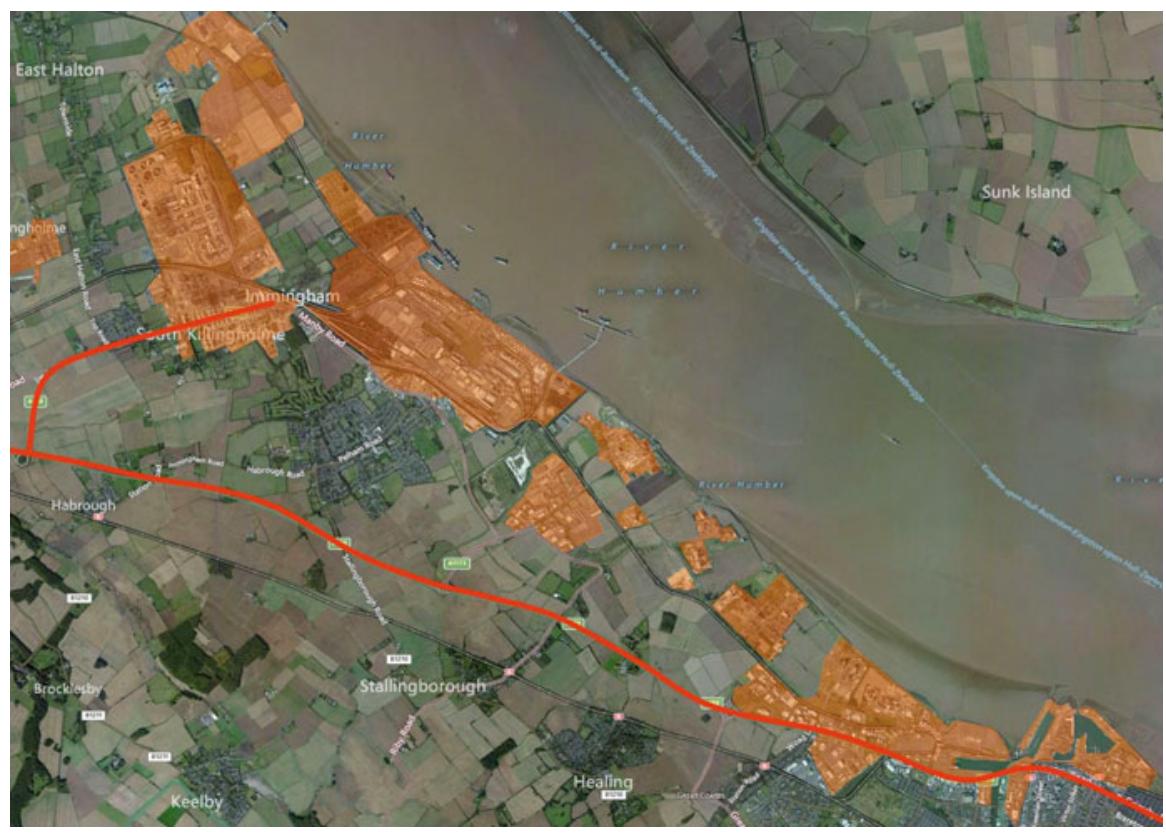

Fig. 19.1 Arial overview of Immingham/South Killingholme (industrial areas in orange) 
towns of Grimsby and Hull. Grimsby, known as Europe's Food Town, is home to a high concentration of food producers, supported by cold storage, logistics, engineering and packaging services. The town is synonymous with seafood, including brands such as Findus and Young's, and represents $70 \%$ of the entire UK seafood processing capacity. Steel processing at Scunthorpe has its origins in the iron deposits of the Jurassic limestone escarpment that is found at either side of the estuary.

Seventeen per cent of UK's power-generating stations including Drax, Eggborough, Ferrybridge, Cottam, Radcliffe, Humber Power and Centrica lie inland from the Humber region. With only $8 \%$ of UK's electricity demand, the Yorkshire and Humber region is a net exporter of power to the rest of the country. The heavy industrial base of the wider Yorkshire and Humber economy is the source of $23 \%$ of the $\mathrm{CO}_{2}$ emissions of England and Wales (89 Mte) (Environment Agency) and over six million tonnes of commercial and industrial waste arisings (Defra 2011, 2014) (Fig. 19.2).

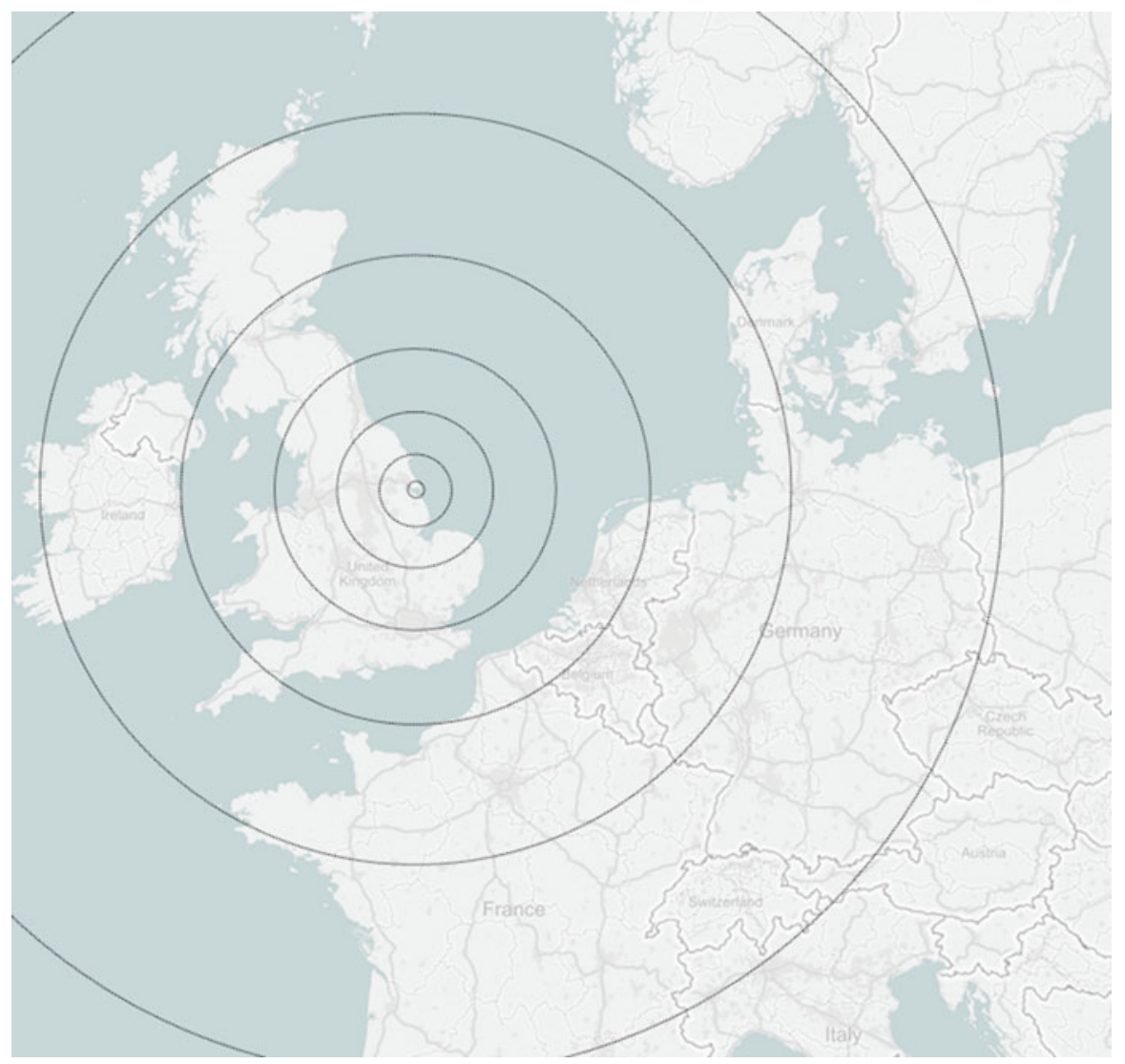

Fig. 19.2 Strategic location of the Humber within the North Sea basin 
Immingham CHP is one of the largest combined heat and power (cogeneration) plants in Europe. The 1,220 MWe facility provides steam and electricity to Phillips 66's Humber Refinery, steam to the neighbouring Lindsey refinery and merchant power into the UK market. With more recent regional investment in wind power and the bioethanol plant at Saltend that add to the existing CCGT and CHP power plants, the Humber has been positioned as the 'Energy Estuary'.

This rich industrial activity of the Humber and the wider Yorkshire and Humber region have made it a natural home for applying industrial symbiosis principles (see Chertow 2007 and Chap. 5). The early work on industrial symbiosis on Humberside around the turn of the millennium was centred on the large capital projects of the region. These included the Immingham CHP plant, studies on a 'Humber bundle' considered to link the chemical and gas generation plants of the north and south bank through a strategic pipelines crossing beneath the river, together with a further major study of material streams within the Humber's chemical industry. This 'topdown' approach, considering major infrastructure initiatives, was later replaced with a 'bottom-up' widespread engagement of industrial partners taken by the NISP-Humber from 2003 onwards (Mirata 2004). This was one of the three pilot regions at the start of the UK National Industrial Symbiosis Programme (NISP); it became the NISP-Yorkshire and Humber region in 2005. Over the subsequent 5 years alone, this programme engaged with 700 companies in Yorkshire and Humber and documented $\mathrm{CO}_{2}$ reductions of 780,000 tonnes per annum for its clients and a reduction of $1,400,000$ tonnes in material being landfilled.

Link2Energy Ltd ran these latter two industrial programmes on behalf of International Synergies Ltd. Initially the funding was from the regional development agency Yorkshire Forward and subsequently from the Department of Food and Rural Affairs (DEFRA). From 2012 Link2Energy Ltd developed its own independent commercial programme Re:Sourcing $U K$ with a focus on high-value opportunities and innovation. It is against this background and experience that Link2Energy Ltd was invited to provide industrial symbiosis expertise into the European FP7funded project LOCIMAP, below.

The strategic importance of the Humber region has also been recognised by a study carried out by the University of Surrey on the Evolution and Resilience of Industrial Ecosystems (ERIE) project. Two further papers draw extensively on the work in the Humber region, 'Habitat' Suitability Index Mapping for Industrial Symbiosis Planning (Jensen et al. 2012) and Quantifying 'Geographic Proximity': Experiences from the United Kingdom's National Industrial Symbiosis Programme (Jensen et al. 2011).

\section{The LOCIMAP Project}

Europe's 2020 growth strategy (EC 2012) commits to limiting greenhouse gas emissions by $20 \%$ compared to 1990 levels, creating $20 \%$ of Europe's energy needs from renewables and increasing energy efficiency by $20 \%$. Within this broad 
strategy, an international non-profit public-private partnership (PPP) has been set up: A Sustainable Process Industry through Resource and Energy Efficiency (A.SPIRE) ${ }^{1}$ with the private sector as a partner. A.SPIRE has set further targets for 2030, below. It was launched as part of the Horizon 2020 framework programme, which is in turn the biggest EU research and innovation programme ever with nearly $€ 80$ billion of funding available over 7 years (2014 to 2020).

A.SPIRE represents more than 114 industrial and research process industry stakeholders from over a dozen countries spread throughout Europe. It was established through the joint efforts of 8 industry sectors: chemical, steel, engineering, minerals, non-ferrous metals, cement, ceramics and water. The mission of A.SPIRE is to ensure the development of enabling technologies and best practices along all the stages of large-scale existing value chains that will contribute to a resourceefficient process industry. Through purposeful cooperation across all sectors and regions, A.SPIRE has developed a strategic roadmap that addresses research, development and innovation activities as well as policy matters towards the realisation of its 2030 targets. The ultimate goal is to promote the deployment of innovative technologies and solutions required to reach long-term sustainability for Europe and its process industries in terms of global competitiveness, ecology and employment. The 2030 targets are:

1. A reduction in fossil energy intensity of up to $30 \%$ from current levels through a combination of, for example, energy-saving processes (including enhanced use of optimisation techniques, monitoring and modelling via ICT tools), process intensification, energy recovery, sustainable water management, cogeneration (i.e. combined heat and power) and progressive introduction of alternative (renewable) energy sources within the process cycle.

2. A reduction of up to $20 \%$ in non-renewable, primary raw material intensity compared to current levels by increasing chemical and physical transformation yields and/or using secondary or renewable raw materials. This may require more sophisticated and more processed raw materials.

The A.SPIRE PPP objective is to develop the enabling technologies and solutions along the value chain, required to reach long term sustainability for Europe in terms of global competitiveness, ecology and employment.

The low-carbon industrial manufacturing parks (LOCIMAP) project was funded by the European Commission under the Framework 7 programme. It was set up to explore this very conundrum, examining not only technical but also economic and business (and even political) factors as it sought to contribute to the development of a roadmap for a closed-loop economy in a major continent with the longest industrial history and a relatively stable population. The project was managed by North East Process Industry Cluster (NEPIC) and included participation from four industrial parks: the chemical park at BASF Española SL in Spain, Wilton in the UK represented by Sembcorp Utilities (UK) Ltd, Kokkola Industrial Park in Finland and Kalundborg Municipality Denmark.

\footnotetext{
${ }^{1} \mathrm{http}: / /$ www.spire2030.eu
} 
LOCIMAP considered the potential for the integration of a number of high CO2emitting industries and had industrial partners within its team to bring in a high level of detail on process operations within the key sectors; these were Cemex UK Cement Limited, Papiertechnische Stiftung (PTS) from Germany representing the pulp and paper industry, VDEh-Betriebsforschungsinstitut GmbH (BFI) the iron and steel industry also from Germany and Terreal of France for the ceramic industry. In addition Phillips 66 provided key information on petrochemical operation. Four technical specialist companies participated in the technical and business analyses: Parsons Brinckerhoff Sp. z.o.o. from Poland, Svenska Miljöinstitutet (IVL) from Sweden, Link2Energy Ltd from the UK and the Institut Europeen D'Administration Des Affaires (INSEAD) from France. External communications were managed by the European Chemical Site Promotion Platform (ECSPP) from the Netherlands. ${ }^{2}$

The project concept was to re-examine the structure of industrial parks using best practice benchmarks from across leading parks in the EU and elsewhere, the focus being to substantially improve energy and resource efficiency, reduce $\mathrm{CO}_{2}$ emissions and improve competitiveness. From the outset, substantial advantages were anticipated through migration towards more completely integrated manufacturing, centred on concentrating activities in new industrial park structures supported by dedicated services optimisation.

At one of the LOCIMAP steering groups, a chance remark was made that what we need to underpin the future of manufacturing in Europe is a new industrial revolution. The context was of course a comment on the magnitude of the change that this project was looking to define in order to make a tangible impact on the competitiveness of European industry. From the outset, the ambition was to much more than the squeezing out of a few percentage points in process efficiency. Rather the goal was to explore the potential for a step change breakthrough.

Conscious of the old adage that 'if you always do what you've always done, then you always get what you've always got', this challenge for an industrial revolution further emboldened the project to be courageous in its thinking. The LOCIMAP project therefore looked to explore a range of parameters that could make such a change and has included not only technical but also economic and business (and even political) factors. At the heart of the analysis was the construction of a 'virtual industrial park' where full optimisation of the industrial processes could be considered with all technical and business constraints removed.

Even before a presentation of the options, the reader may already, and rightly, be thinking that any such technical changes, no matter how good, may be replicated globally; therefore any grounds for optimism may be a respite rather than a longterm solution and still leave us with the original question as to how we secure the competitiveness of the European manufacturing base. The response to this is, in part, to refer to the potential of the closed-loop economy. Europe alone, of all the major continents, has a relatively stable population; if we consider that we have all the materials we need within the economy, then we can indeed close the material

${ }^{2} \mathrm{http}: / / w w w . l o c i m a p . e u$ 
loops. Coupled with the high-value innovative and entrepreneurial landscape that we need to make this happen, do we indeed have the basis for this new industrial revolution? This question and how we might take steps towards this within a lowcarbon economy are addressed in general in Chaps. 6 and 7. The LOCIMAP project sought to address the question specifically within the context of industrial parks.

\section{LOCIMAP: Guiding Principles}

Industrial symbiosis was recognised as the key principle to achieving this industrial revolution by the LOCIMAP project. It represents the cornerstone of not only a lowcarbon industrial manufacturing park but a low-carbon economy. This business principle, if not the name, has been in operation as long as industry has existed; it is greatly underexploited.

A number of sectors have prepared roadmaps to a low-carbon industry, e.g. Cement Technology Roadmap 2009 (OECD et al. 2009), Steel's Contribution to a Low-Carbon Europe 2050 (Wörtler et al. 2013), Paving the Way to 2050: The Ceramic Industry Roadmap (Cerame-Unie 2012), Unfold the Future: The Forest Fibre Industry 2050 (CEPI 2011) and Roadmap to a low-carbon bio-economy: An Aluminium Roadmap to a low carbon Europe: Lightening the Load (EAA 2012). These are highly professional documents, but (with the possible exception of the cement industry and to some extent the paper industry) they are in many cases limited in their vision, principally restricting the analysis to their own sector. To be truly effective, industrial symbiosis needs to be cross-sectoral. More than that, it should go beyond the optimisation of resources in a given location to the selection of the location at the point of business investment. Ultimately, the driver for the uptake is simply that of best practice business delivering both competitivity and environmental benefits.

The requirement is to deploy the principles of industrial symbiosis in a bold and strategic way. For example, why shouldn't the blast furnace off-gas from the iron and steel industry be used as syngas within the chemical industry? To illustrate the point, many factories within the chemical or petrochemical industry have as the unavoidable result of established processes - and despite the efforts of generations of engineers - significant quantities of low-grade heat. Similarly, many food factories have a demand for cooling. The potential for the chemical industry supplying refrigeration capacity through absorption chilling opens up a solution that is not available within single sectors. This is a far-ranging comment since it implies a breadth of imagination at not only the business and engineering level but also that of strategic planning. Though it may not be always practicable for two sectors to be cheek by jowl geographically, this does not prevent them from having a thermodynamic umbilical link. Again, these examples draw in the requirement to be strategic and to include local government, planners and politicians alongside business and engineering. 
For industrial symbiosis to deliver its full commercial potential in terms of engineering efficiency, it needs to move beyond the first-generation approach of material transfer. This is certainly not to dismiss the benefit of 'long-radius' synergies involving material transfers from further afield; the positive carbon credit for use of material by-products against the extraction and processing of virgin materials is eminently quantifiable. However, real progress is only achievable by including the integration of heat and power in 'short-radius' synergies with associated heat and power supply networks in dedicated industrial eco-parks. It will clearly be an economic impossibility to optimise utility systems that rely on close proximity between partner organisations unless they really are co-located. The park concept is key to this. Furthermore, within a $\mathrm{CO}_{2}$ minimisation agenda, supply chain integration is likely to be subservient to the industrial symbiosis objective. This is not the case now, where logistics represent the primary threads holding the supply chain together. This shift will require reconfiguration or even a redefinition of the supply chain, but this will need an effective powerful driver either of long-term policy or of carbon price.

Residual 'low-grade' heat presents a major opportunity for further improving the already good $\mathrm{CO}_{2}$ performance of our industrial parks. However, we suggest that a change in mindset is needed so that its use is considered from the outset, as part of the overall process design. Whilst district heating systems for residential areas are good, they suffer from high seasonality of demand; what is required is a constant demand of industrial proportions. The example already cited, regarding the development of district cooling systems powered by residual heat through absorption chilling systems, requires bold planning moves such as co-location in the food industry, with its typically high demand for refrigeration, cold stores, data centres, etc., alongside the sources of residual heat, particularly the chemical, petrochemical and power industries.

As a consequence of this study, Link2Energy Ltd has proposed such a system for the South Humber Bank; waste heat from the petrochemical plants is being considered to provide cooling for a cluster of food companies $10 \mathrm{~km}$ away with the two sites potentially linked through a utility corridor within the coastal industrial strip.

However, not all residual heat is low grade. By way of example, the energy flows through an integrated steel complex dwarf those of most other industries, and the ability to recover waste heat from the cooling of products and from the slags, though inevitably difficult and a technological challenge (that is being grasped), is a significant source of potential high-grade heat and hence of reduced emissions.

The recovery of heat is clearly only of value if there is a home for it. Industrial clustering on parks is paramount to capitalise on this potential. The challenge is clear: how can we better integrate our industries and deliver collective $\mathrm{CO}_{2}$ emission reductions rather than leave industries isolated and subject to carbon leakage pressures?

Furthermore, each future park may benefit from having its own technology centre for evaluating the optimum utility configurations of the resident industries in a dynamic setting, for assessing new opportunities for the valorisation of by-products and for the deployment of new technology. There are certainly examples of this across Europe (e.g. CPI at Wilton, Chemelot Campus, etc.) 
Most of the specific sector roadmaps cite technology advances within their plan for 2020 and 2050 targets. In most instances, the ways suggested to bring about a reduction in $\mathrm{CO}_{2}$ footprint are sector specific. An example is the ULCOS project. ${ }^{3}$ ULCOS stands for ultra-low carbon dioxide $\left(\mathrm{CO}_{2}\right)$ steelmaking. It is a consortium of 48 European companies and organisations from 15 European countries that have launched a cooperative research and development initiative to enable drastic reduction in carbon dioxide $\left(\mathrm{CO}_{2}\right)$ emissions from steel production. The consortium consists of all major EU steel companies, of energy and engineering partners, research institutes and universities and is supported by the European commission. The aim of the ULCOS programme is to reduce the carbon dioxide $\left(\mathrm{CO}_{2}\right)$ emissions of today's best routes by at least $50 \%$. Other initiatives include the deployment of high-efficiency kilns as examples of material changes such as the development of artificial pozzolans within the cement industry (OECD et al. 2009). However, if the challenge is to deliver a low-carbon economy, then the ultimate requirement is to base the design of that (industrial) economy on thermodynamic principles (Bakshi et al. 2011).

LOCIMAP brought together an array of existing and emerging technologies that individually offer an ability to recover and to transfer heat from one process to another and which are key to achieving the ambition for integration. Further, the management of such integrated systems will demand an overarching control philosophy and deployment of ICT (see LOCIMAP White Paper 3).

Link2Energy Ltd is active in developing opportunity within both the Humber and Tees river basins for the deployment of flameless oxy-combustion FPO systems. Suitable for a wide variety of wet waste materials including renewables, the technology is capable of very high operating efficiency and low emissions due to the absence of nitrogen. It has also pioneered the development of hydrothermal carbonisation for the treatment of organic materials including poultry litter and is applicable in several industries within the Humber hinterland.

Process techniques such as pinch technology make it possible to define minimum utility consumption for individual processes and also the optimum energy target for integration of quite disparate processes. This powerful technique has been used extensively within the process industries in particular. LOCIMAP extended the technique to the application across a virtual industrial park. The end result is a powerful blueprint for integrating processes from the chemical, petrochemical, pulp and paper, fine chemical and biofuel sectors together with some from the iron and steel and non-ferrous metal industries.

The LOCIMAP project has sought to minimise the release of carbon through intelligent synergies between industries. Processes are under development elsewhere to use $\mathrm{CO}_{2}$ as a feedstock. Some products may be manufactured from fluegas $\mathrm{CO}_{2}$, e.g. cyclic carbonates, but the market for these products is small in comparison with present emissions. Carbon capture and storage is the ultimate backstop, and many of the individual sector roadmaps forecast the importance of this technology within their 2050 view on $\mathrm{CO}_{2}$ reductions. It may become increas-

${ }^{3}$ http://www.ulcos.org 
ingly important, and indeed an asset, for future industrial parks to be geographically located on a carbon capture and transportation highway umbilically linked to a carbon storage facility. Carbon management and $\mathrm{CO}_{2}$ sequestration will be at the heart of a future low-carbon industrial park and become part of the utility system.

In the Yorkshire and Humber region, National Grid is helping to develop solutions to reduce the carbon dioxide $\left(\mathrm{CO}_{2}\right)$ emissions from power stations and industrial plants. A solution being explored is carbon capture, transportation and storage (CCS) technology - capturing carbon dioxide emissions and transporting them to be stored permanently beneath the seabed in natural porous rock formations or depleted oil and gas fields. If approved, the Yorkshire and Humber CCS Cross-Country Pipeline project ${ }^{4}$ will involve the construction of a cross-country pipeline and a subsea pipeline to transport carbon dioxide from fossil fuel power stations and industrial plants in the region to a permanent geological storage site beneath the North Sea. The onshore pipeline would be $75 \mathrm{~km}$ long and would use the same sort of technology as the national high-pressure gas pipeline network, owned and operated by National Grid. It would be up to 24" (about $600 \mathrm{~mm}$ ) in diameter and buried at least $1.2 \mathrm{~m}$ below ground. The carbon dioxide would be transported in liquid form at a pressure of $150 \mathrm{barg}$. The subsea pipeline would be the same size and on the seabed. Offshore, the carbon dioxide would be transported at a pressure of up to 200 barg to a geological storage site beneath the North Sea. The pipeline would have the capacity to transport up to 17 million tonnes of carbon dioxide every year. The longterm aspiration is for the pipeline to form the foundation of a regional CCS network, potentially capturing tens of millions of tonnes of carbon dioxide every year.

As noted above, the major themes within LOCIMAP, the optimisation of steam and power systems, cannot be realised within supply chain integration unless the manufacturing units are co-located. It will clearly be an economic impossibility to integrate utility systems that rely on close proximity between partner organisations unless that is the case. Within the $\mathrm{CO}_{2}$ agenda, supply chain integration is subservient to the industrial symbiosis question. This may even lead to a reconfiguration or even a redefinition of the supply chain.

The waste industry will play an increasing role within the industrial landscape of such symbiotic parks through the provision of feedstock. Whilst industrial symbiosis and the exchange of industrial by-products as feedstocks are vital in future industrial parks, the importance of post-consumer waste as a feedstock will also grow. For some elements, e.g. copper, it is recorded that there is more material in the technosphere rather than the geosphere, and there is much concern over the availability of a range of other 'critical raw materials'. In some cases the concentration of these materials is greater in post-consumer and industrial wastes than in the virgin ore; some process are natural concentrators of the ore, e.g. the levels of germanium and gallium in coal ashes are inevitably almost 100 times that in the coal. Despite many critical raw materials being nonindigenous to Europe, recycling and recovery rates of such elements and compounds are still amazingly low.

${ }^{4}$ http://www.ccshumber.co.uk 
These changes in feedstock supply will have a bearing on energy demands and $\mathrm{CO}_{2}$ emissions. The aluminium industry is a good and current case of an industry that has already shifted focus towards a recycled feedstock and shows the improved economics and environmental performance through recycling of aluminium (e.g. cans) compared with the life cycle implications of producing virgin metal (see Chap. 6).

Resource innovation, the recovery of component parts of 'waste streams', whether that is critical raw materials from mineral based industries, proteins and flavonoids from industrial food wastes or phosphates from water discharges, represents an improvement in utilisation of finite resources which will need to shape future policy and approach. Avoiding the closure of material loops is not a future option; this is not a matter of principle, but ultimately one of economics and the emerging industries will be integral to a changing mix on the future industrial park.

Again, to lean on the thermodynamic argument for materials as well as for our utility studies, the more dissipated our resources, the higher the entropy and the more the energy required to recover them. It is surely better to sprout a new industry on a collocated industrial park to recover critical material from fly ash before we provide it as an ingredient to make cement.

Link2Energy has a legacy of successful material exchanges that minimise material being sent to landfill. However more recent examples of resource innovation in the Humber area relate to the development of a marine biorefinery for the extraction of phospholipids from fish and particular salmon skins. The project, which was funded by the Innovate for Growth competition run by the Technology Strategy Board, engaged a Grimsby-based food factory, academia and a local company specialising in extraction technology. It has replicated this collaborative approach with academia and industry for a number of other high-value resource innovation projects. These include the extraction of proteins and peptides from reject potatoes, flavonoids from waste citrus fruit and rare earth metals from by-product residues from the mineral industry. The company is also engaged with valorisation of alkaline leachates from the steel industry as part of a 3-year study funded by the Natural Environment Research Council (NERC).

To realise the benefits identified in LOCIMAP, it will be necessary to challenge existing approaches to business. These challenges are twofold. The intra-park challenge goes beyond utility platform sharing and into process integration. The extrapark collaboration goes beyond intercompany exchange into public-private sector partnerships.

The key advantage of the low-carbon park is that it provides the location where minimum energy and lowest cost can exist together. The model for that business may take many forms and will be determined by culture and public sector policy and support. Enlightened self-interest may prove sufficiently strong to engineer some of these changes. LOCIMAP has excellent exemplars from within its own partners as to what can be achieved already through industrial and industrial-municipal collaborations; examples are provided by the parks at Tarragona, Kokkola, Wilton and Kalundborg. 
But, as outlined in LOCIMAP White Paper 4, the low-carbon future requires developments of new approaches and public engagement that can be effective in delivering business solutions at the park level. The project view is that the establishment of 'Synergy Management Services' organisations is probably the best way to go. These need to be led by the park operator or by the industrial cluster with support from the local public sector with an interest in sustainability themselves.

One such example is the Saltend Chemicals Park, a cluster of world-class chemicals and renewable energy business at the heart of Humberside, established by BP Chemicals Ltd in 2009. Today a number of leading organisations operate on the 370 -acre site, sharing an established infrastructure and extensive provision of services, feedstocks and utilities, enabling them to drive down costs, increase efficiency and boost profitability. The site has seen $£ 500$ million of investment in recent years and its products range from clothing to paints, pharmaceuticals and packaging.

\section{Prospects}

If the size of the prize from this level of integration were small, there would be little drive for pursuing the concepts outlined. However, the conclusion of the LOCIMAP work suggests that the prize is very high. In fact, it is so high that such integrated systems could deliver not only the EU 2020 targets but those set by the SPIRE project also. In contrast with the ever-increasing squeeze on existing assets through traditional resource efficiency, the benefit achieved by the coordinated and symbiotic co-location promises major benefits at both thermodynamic and business levels (Fig. 19.3).

Such a strategic shift raises big questions. How can we engineer such systems without compromising safety? What are the implications for system resilience? How can such a closely integrated arrangement manage operational necessities such as maintenance schedules? Such questions would need to be answered in time - for the present, it is sufficient to recognise the scale of the prize on offer through such an approach.

What happens if we do not take this bold approach? The project highlighted the concerns by its partners regarding carbon leakage, and this is seen as a hidden barrier. Each manufacturer, and each park, provided information on the legislative and taxation structures within which they operate. They commented on their driving forces in terms of the costs involved in related investments for improvement and in buying carbon credits. Beyond that, they were invited to outline any company or sector initiatives at the 2050 time horizon. In essence the feedback to the project confirmed that carbon trading has the potential to increase economic pressures on the more energy-intensive sectors to leave the European economy. This will disproportionately affect parks.

The project further examined present and future potential by-product linkages between the sectors represented within LOCIMAP. Whilst the loss of an industry 


\section{Impact of Integration on Heat Demand in the LOCIMAP virtual Park}

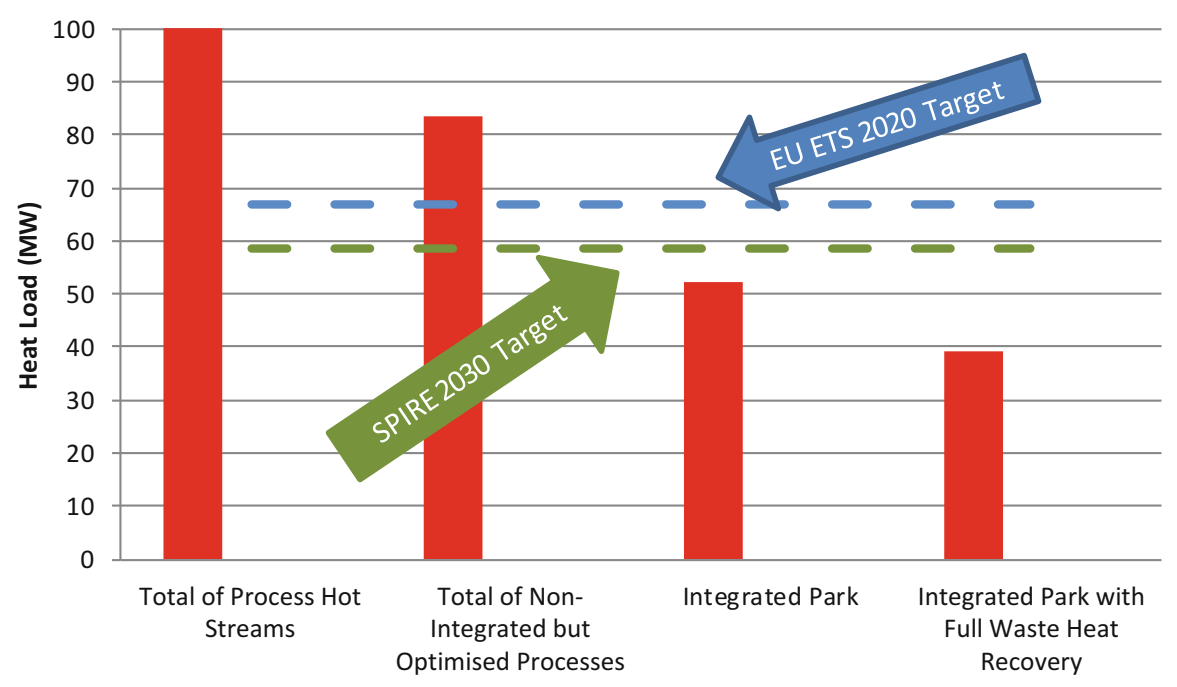

Fig. 19.3 Impact of process integration within a virtual 'LOCIMAP' park

sector from the European industrial mix has negative impact enough on the social and economic perspective, the LOCIMAP studies have further highlighted the loss that an industry makes on the overall potential integration and optimisation which is far wider that when considering the industry in isolation. The loss in potential not only for heat and power integration but for material by-product integration and the closing of material loops has a quantifiable and negative impact on environmental performance of the whole. LOCIMAP makes the case for the evaluation of the impact of $\mathrm{CO}_{2}$ emissions not only 'up the stack', which the EU ETS addresses, but also enabled by that industry's presence; in essence, this is an argument for a consequential approach to evaluation (see Chaps. 2 and 3). The case is made for the retention and development of those industries which are world leading in terms of $\mathrm{CO}_{2}$. Diversity of industry types is seen as the cornerstone of successful and resilient industrial symbiosis exemplified by a low-carbon park; the positive impact on resilience is undervalued by the omission of by-product synergy quantification.

\section{Conclusion}

We conclude that the application of these principles, through the appropriate design of industrial parks and the development of opportunities for process integration, has the potential to exceed the targets set within EU ETS under which the majority of 
our participating industries operate and also the targets within SPIRE. The question is: what are the barriers to achieving this? The project sees three major challenges to existing business models:

- This low-carbon future requires developments of new approaches and public engagement that can be effective in delivering business solutions at the park level. Some of the beneficial opportunities are already available and could be implemented now within existing industrial clusters. What is needed is a culture change to think and work cross-sectorally. This process is not easy and will need stimulus but is essentially one of knowledge transfer. The mechanism is one of allowing normal business drivers to effect change once opportunities are visualised. The establishment of 'Synergy Management Services' organisations is probably the best way to go. These need to be led by the park operator or by the industrial cluster with support from the local public sector with an interest in sustainability themselves.

- The second barrier lies beyond industrialists, engineers and business owners and relates to local and national government and planning. A new investment is not best served by offering location at a number of greenfield sites, rather by the optimum integration with existing facilities. The answer to a low-carbon economy is a thermodynamic one, and planning needs to allow for this, even to the extent of (physically) linking, for example, the chemical and food industries. Policies need to be created which encourage such developments.

- The third barrier is that some of the opportunities are not economic under the existing landscape. This becomes a societal and a political issue. What is the price of carbon? If we really want a low-carbon economy, how do we introduce measures that deliver the low-carbon benefits without disadvantaging European manufacturing within a global playing field? The fundamental issue is that, given a brief to design the most economic system, the outcome will be different from designing the lowest carbon system. The work shows that we have the engineering capability to deliver low-carbon systems; the question is a societal one as to whether we have the will and understanding to change the rules to align economic and environmental performance.

Can we go so far as to say we have the ingredients for a new industrial revolution? Does delivering low-carbon manufacturing within the landscape of 'closing loops' contribute to this? What is the future role of the waste industry? The LOCIMAP project sought to inform opinion on all these points. It goes beyond the bilateral synergies rightly documented as exemplars to a much more strategic approach to energy and resource efficiency that demands that the requirement for a low-carbon industry inform primary planning and design specifications.

So the question is: what do we need to do to deliver a low-carbon manufacturing park? The answer is not 'green', or '42'; it's thermodynamic! The task is to communicate this to policymakers and to translate these principles back to the source of their inspiration: concrete experience from the contributing industrial parks of Tarragona, Wilton, Kokkola and Kalundborg and of course to the Humber. 
Acknowledgements The work presented draws extensively but not exclusively on White Paper 5 of project 296010 LOCIMAP. This coordination and support action was funded by the European Commission under the Framework 7 programme; their support is appreciated. The partners in the project are NEPIC, BASF, Link2Energy, ECSPP, INSEAD, Sembcorp, PTS, IVL Svenska, Kokkola Industrial Park, Kalundborg Kommune, Parsons Brinckerhoff, Cemex, Terreal and BFI. This report acknowledges the collaborative effort of all the above organisations.

Open Access This chapter is distributed under the terms of the Creative Commons Attribution Noncommercial License, which permits any noncommercial use, distribution, and reproduction in any medium, provided the original author(s) and source are credited.

\section{References}

A full list of White Papers from the project is available from www.locimap.eu: White Paper 1: The challenges facing the European Industrial Parks; White Paper 2: Industrial Symbioses; White Paper 3: Smart Future Industrial Parks; White Paper 4: New Operational \& Organisational Structures; White Paper 5: 10 Principles for a Low Carbon Future.

Bakshi, B. R., Gutowski, T. G., \& Sekulic, D. P. (Eds.). (2011). Thermodynamics and the destruction of resources. New York: Cambridge University Press.

CEPI. (2011). Unfold the future: The Forest Fibre Industry, 2050 roadmap to a low carbon bioeconomy. Brussels: Confederation of European Paper Industries. Retrieved April 20, 2015, from http://www.unfoldthefuture.eu/uploads/CEPI-2050-Roadmap-to-a-low-carbon-bioeconomy.pdf

Cerame-Unie. (2012). Paving the way to 2050. The ceramic industry roadmap. Brussels: European Ceramic Industry Association. Retrieved April 20, 2015, from http://www.ceramfed.co.uk/ uploads/popular_downloads/04ed1d019530eec2cfe5fd2f4e174a19bbd363ae.pdf

Chertow, M. R. (2007). “Uncovering” industrial symbiosis. Journal of Industrial Ecology, 11(1), $11-30$.

Defra. (2011). Commercial and industrial waste survey 2009. London: Department of the Environment, Food \& Rural Affairs.

Defra. (2014). New methodology to estimate waste generation by the commercial and industrial sector in England. London: Department of the Environment, Food \& Rural Affairs.

EAA. (2012). An Aluminium roadmap to a low carbon Europe: Lightening the load. Brussels: European Aluminium Association. Retrieved April 20, 2015, from http://www.alueurope.eu/ wp-content/uploads/2012/03/03_An-aluminium-2050-roadmap-to-a-low-carbon-Europe.pdf

EC. (2012). Europe 2012: Europe's growth strategy. Brussels: European Commission.

Jensen, P. D., Basson, L., Hellawell, E. E., Bailey, M. R., \& Leach, M. (2011). Quantifying 'geographic proximity': Experiences from the United Kingdom's National Industrial Symbiosis Programme. Resources, Conservation and Recycling. doi:10.1016/j.resconrec.2011.02.003.

Jensen, P. D., Basson, L., Hellawell, E. E., \& Leach, M. (2012). 'Habitat' suitability index mapping for industrial symbiosis planning. Journal of Industrial Ecology, 16(1), 38-50.

Mirata, M. (2004). Experiences from early stages of a national industrial symbiosis programme in the UK: Determinants and coordination challenges. Journal of Cleaner Production, 12(8-10), 967-983.

OECD, IEA, \& World Business Council for Sustainable Development. (2009). Cement technology roadmap 2009: Carbon emissions reductions up to 2050. Retrieved April 20, 2015, from http:// www.wbcsdcement.org/pdf/technology/WBCSD-IEA_Cement\%20Roadmap.pdf

Wörtler, M., Schuler, F., Voigt, N., Schmidt, T., Dahlmann, P., Lüngen, H. B., \& Ghenda, J.-T. (2013). Steel's contribution to a low-carbon Europe 2050: Technical and economic analysis of the sector's CO2 abatement potential. London: BCG. Retrieved April 20, 2015, from http:// www.bcg.de/documents/file154633.pdf 